\title{
TECHNOLOGY OF SPATIAL DATA GEOMETRICAL SIMPLIFICATION IN MARITIME MOBILE INFORMATION SYSTEM FOR COASTAL WATERS
}

Witold Kazimierski, Ph. D. Eng.

Marine Technology Ltd., Poland

Marta Włodarczyk-Sielicka, M.Sc. Eng.

Maritime University of Szczecin, Poland

\begin{abstract}
The paper undertakes the subject of spatial data pre-processing for marine mobile information systems. Short review of maritime information systems is given and the focus is laid on mobile systems. The need of spatial data generalization is underlined and the concept of technology for such generalization in mobile system is presented. The research part of the paper presents the results of analyzes on selected parameters of simplification in the process of creating mobile navigation system for inland waters. In the study authors focused on selected layers of system. Models of simplification for layers with line features and with polygons were tested. The parameters of tested models were modified for the purposes of study. The article contains tabular results with statistics and spatial visualization of selected layers for individual scales.
\end{abstract}

Keywords: simplification; maritime information systems; mobile systems; generalization

\section{INTRODUCTION}

Navigational systems are a specialized kind of Geographic Information Systems (GIS), focused on presenting real-time positional data on map background. From this point of view it can be noticed that also maritime information systems are in fact an examples of GIS technology. Although it is not referred directly by IMO (International Maritime Organization), IHO (International Hydrographic Organization) or IALA (International Association of Lighthouse Authorities) in their performance standards, the basics of systems like ECDIS or VTS rely on GIS technology. The main problem in these systems is proper handling of spatial data to provide desired cartographic products and spatial analysis results.

The scope of using GIS methodology in maritime environment is even wider nowadays, when an e-navigation concept is being widely examined and developed in IMO forum and outside of it. At the moment the concept of bringing more ICT into navigational technology is resulting in many test applications delivered in various $\mathrm{R} \& \mathrm{D}$ projects also for mobile devices.

One of the main problems in any maritime information systems as well as in other GIS systems is delivering of up-todate model of spatial data for these systems. The most popular approach used mainly in conventional systems is to implement the model proposed by IHO in ENC and ECDIS standards. They include both, data and cartographical model, used in conventional navigation systems. Other applications however may use other data or cartographic models, dedicated for 
particular user needs. The spatial data, used in the system, usually coming from various databases has to be integrated and prepared for cartographic visualization. One of the key issues in preparing of cartographical model from existing data sets is called generalization.

In general, map generalization may be defined as adapting the content and the level of detail of a map to suit its scale and purpose. Generalization is one of the most important and yet one of the most difficult subjects in cartography. One of the main problems is that it cannot really be fully automatized - it rely much on the decisions made by operator and visual check of cartographic presentation. Nevertheless, one of the assumptions in project was that all processing, including generalization, shall be as much automatized as possible. Thus suitable models and algorithms have been provided to perform this task [1].

The paper shows the entire path of working on generalization in an example mobile navigational system for coastal waters. The description is started with theoretical model of generalization, through the proposed approach to simplification, up to experimental research and it results, showing the efficiency of the method used. The idea was to present the possibilities of spatial data handling in any maritime systems, however the research themselves are focused on system for mobile devices as the kind of device is also an important factor in generalization process and the mobile devices are the future of navigation. Although the paper describes generalization in general, the research focuses on geometrical simplification as one of the methods of generalization.

\section{MARITIME INFORMATION SYSTEMS}

Maritime information systems are understood in this paper as the systems in which maritime spatial data are managed and visualized. This means that any GIS covering maritime area and processing spatial data affecting sea environment can be treated as maritime information system. The most popular examples here can be Electronic Chart Display and Information System (ECDIS) on board of the ship used for navigation or Vessel Traffic Management System (VTS or VTMS) ashore used for traffic management.

In general, maritime information systems may be divided into conventional and non-conventional systems. Conventional are these, which follow any particular standard given by international body, like ECDIS standard by IHO [2] or VTS standard by IALA [3]. There is however more and more applications used by so called non-conventional users that use other systems for navigational purposes. These also can be understood as maritime information systems, and as nonstandardized, they require more attention in the process of spatial data management. It should be added anyway that in both kinds of systems a quality of data is a key issue for usefulness of the system. Traditional sources of data, like ashore and off-shore surveying are nowadays exchanged or supplemented with modern techniques, among which remote sensing performs the leading role. The devices like laser scanner, spectral cameras, high-speed cameras etc. are a crucial source of spatial data used in official ENCs, topographical databases, but also in non-conventional databases. The advantages of these methods can be found in [4] with an application also for maritime areas.

An important issue that has to be undertaken in deliberations about maritime information systems is the mobility of them. It can be noticed, that in fact any ship system can be treated as mobile, as it is not used stationary, but on the moving platform. However, when talking about spatial data handling, it is more reasonable to connect mobility to the cartographical model and to the device on which the system runs as it is in the concept of mobile cartography $[5,6]$.

\section{A. Shore systems}

The most popular maritime information shore system is VTS. Standardized by IALA, VTS aims at providing real-time information about traffic in the particular sea-area to the VTS operator in shore center. The main information function, may be enhanced by traffic management or other features (like navigational assistance), depending on legal issues and needs in particular VTS area [7]. The system is stationary and the cartographic model is static and usually based on ENC.

In the coastal areas however also other systems, not only for supporting navigation, may be found. In general they can be treated as a group of so called coastal GIS systems and mostly focus on environmental modelling [8]. They are usually specialized in a particular aspect of maritime environment and in general aims at providing comprehensive knowledge about it. Data model here is usually more complicated and includes also properly formatted spatial data from other databases than ENC. The model is sometimes supplemented with raster data $[9,10]$.

Interesting examples of wider concept of information system are also River Information Services. RIS may be defined as a collection of ICT systems for providing various information to wide scope of users in river navigation and transportation. These systems require also special handling of spatial data, not only for Inland Electronic Navigational Charts, but also for spatial analysis $[11,12]$.

\section{B. On-board systems}

The most numerous group of information systems at sea are on-board systems, used for obtaining spatial information around own ship. Most of them aim at navigational purposes, but there are also examples of other interesting applications. Once again the division between conventional and nonconventional systems can be made.

\section{1) Conventional on-board infromation systems}

The development of conventional navigational information systems started when traditional electronic devices, like radar begun to provide more and more information. Nowadays tracking radar used on board is in fact an ICT system in which radar antenna is one of input sources, while others like AIS or ENC database are also used. The differences between radars 
and ECDIS still exists, as their origin is different, however it can be noticed that the scope of information they provide are more and more similar [13]. Thus, many systems integrating this information appeared. Among them the conventional example is Integrated Navigational System (INS). According to Resolution MSC.252(83), INS is a navigational system, which provides multifunctional displays integrating at least the functions of route planning and collision avoidance [14].

From spatial data handling point of view, all conventional systems have to follow data and cartographic model provided in ENC standard, which makes it inflexible for other purposes. The issue common for all conventional and non-conventional systems is the requirement of real-time presentation of dynamical data, which requires separate algorithms for data quality control and uncertainty management $[15,16]$.

\section{2) Non-conventional navigational systems}

Apart from traditional conventional systems there is a variety of additional features, which have not been adopted by IMO yet, but which are being developed in $\mathrm{R} \& \mathrm{D}$ projects. Important enhancements of standardized systems for navigational purposes are for example Navigational Decision Support Systems. They provide recommendation on vessel movement, taking into account vessel safety, rules of the road and route efficiency $[17,18]$. These system usually use traditional data model, however they can be more flexible and provide non-standardized cartographic model. The crucial information here is dynamic data about own ship and target ships. This requires advanced fusion algorithms which provide reliable data suitable for cartographic presentation $[19,20]$.

\section{3) Survey systems}

Talking about non-conventional systems, it should be also mentioned about complete software toolbox for offshore hydrographic survey on board of research vessels. These systems collect data from connected instruments and sensors, e.g. navigation systems, weather sensors, sound propagation sensors and hydrographic instruments. They store all data in a relational database. Often the products have the possibility of integration with WMS/GIS and other software solutions through import and export of standard data formats. The basic for all these systems is very accurate bathymetric chart providing data about seabed as a basis for any survey job [21, $22,23]$

\section{E-navigation systems}

E-navigation is a wide concept undertaken by IMO to provide legal and technological framework for introducing more ICT technologies into maritime solutions and applications. Any particular standards and solutions have not been adopted yet, but, as a concept has been developed for several years already, some applications have been already proposed and tested. The works are carried in working groups with the leading role of IMO, as well as in R\&D projects. IMO has adopted in strategy implementation plan [24], five basic solution towards which the works are carried out. On of this solution is integration and presentation of integrated information in graphical displays received via communication equipment, which means also working on cartographic model on navigational displays.

Recent works in the field of e-navigation provides interesting results in the field of so called Maritime Cloud, which is a service for exchanging maritime spatial data. The concept is however more technical-centered that cartographic. Some interesting issues about mobility have been anyway undertaken in so called Maritime Android Approach inside Maritime Cloud.

\section{Maritime mobile information systems}

The popularity of mobile devices like smartphones or tablet, enforced maritime community to employ these devices also at sea. The survey undertaken for the purpose of this paper has shown that mobile information systems at sea are mostly commercially sold support systems for non-conventional users, mainly tourists, sailors, and leisure boats owners. The systems are dedicated for mobile devices, however it must be said that most of them do not follow the achievements of mobile cartography, and in such case does not fully use the possibilities given by mobile devices. Most of them are also provided with own-made charts and some use official S-57 charts. In some cases vector information is also supplemented with raster charts, while some use only RNC's. Typical chart information is enhanced with route data, weather and hydro meteorological information.

The research has shown that no advanced cartographic model is used in these applications and the focus is laid mostly on functionality and not on presentation itself. This leads to the conclusion that improvement of cartographic model is possible. Based on these and on questionnaire research, the assumption has been made that improvement of cartographical model would lead towards better usability of the systems.

Regardless of what cartographic presentation model is used, the pre-processing of spatial data imported from any vector database should be made. Taking into account future presentation of data this shall include also generalization algorithms to prepare the cartographic model. These issues are even more important in mobile systems, where the possibility of real time data modification is restricted. Thus the generalization process shall be performed in the stage of data pre-processing. Large number of features and its complexity in wider areas may be significant computational challenge for average mobile device. Especially, if one takes into account, that one of the major requirements for the system is working fluently online in real time. In such a situation the number of features and vertices shall be significantly reduced with the scale, which leads to simplification as a part of generalization.

\section{RESEARCH CONCEPT}

The research presented in the paper aimed at showing possible generalization concept for mobile navigational system and at analyzing of geometrical generalization methods for this 
purpose. The research has been made with mobile navigational system MOBINAV, which was selected as an example of systems dedicated for mobile devices and touristic purposes. An area of Szczecin harbor was chosen as a testbed. The research focused on restricted areas of coastal waters as there are much more complicated in geometry and as such, the spatial data from these areas are much more difficult to process in mobile system. By choosing it the authors were expecting receiving of more valuable results. The assumptions of an experiment itself are given in the further part of the paper.

\section{A. MOBINAV as an example of mobile maritime information system}

Mobile navigation MOBINAV is an example of GIS (Geographic Information System) designed for mobile devices. It was originally created for inland waters, however it performs well also in maritime coastal waters. Development of the new system called MOBINAV was a fundamental objective of R\&D project. The main assumptions of the system are based on its destiny - system is dedicated for recreational users with so called pleasure crafts. The project aims at developing such technology to implement modern mobile cartographic presentation model into navigational system on mobile devices. From final user's point of view, the system will be yet another application for navigation, but this time it will be tailored to him/her and the cartographic presentation will be significantly better than in other applications.

During the work on building of the system it was decided to elaborate an own model of spatial data MODEF (MO-binav Data Exchange Format). The model of mobile cartographic presentation described in [25] was used as a base and modified for the purpose of model implementation in MOBINAV. Large dynamic of mobile presentation enforces frequent change of scale of observed presentation. This leads to a need of generalization of input data, including spatial simplification. The research presented in the paper focus on this aspect of generalization as the most computational-demanding issue.

\section{B. Data simplification issue}

In mobile navigation system MOBINAV, the authors focus on ensuring efficiency of cartographic communication, which has relationship with the effectiveness of contents, utility of chart and its usefulness to the user. During the development of the system model the needs of future users were taken into account, including the purpose of using and technical capabilities of mobile devices. Process of generalization is needed in order to ensure a flexible presentation mode for a user in a situation, when geospatial information has to be visually communicated on a small-display device.

Spatial simplification is one of the generalization techniques. During this transformation process number of vertex in a line that is approximated by a series of points is reduced. Unnecessary coordinate information from line features is removed, whilst maintaining the perceptual line's character. The main advantage of using the simplification is contributed to increase of readability map. Additionally, some practical considerations of simplification include reduced storage space or faster plotting time.

\section{PROPOSAL OF DATA SIMPLIFICATION}

Generalization of map content depends on its purpose, scale, level of details and data. All of these factors have been included in Fig. 1, presenting general schema of generalization in MOBINAV. The purpose is directly related with selection of source data and term of partial geocompositions, scale refers to definition of geocompositions and SCAMIN/SCAMAX definition, while level of details and data may be combined with each element of created schema. Therefore, the generalization process of spatial data in the system can be considered at several levels (Fig. 1).

The first step of generalization was determination of the values of SCAMIN and SCAMAX attributes. These attributes are responsible for the appearance of the object or its disappearance from the geovisualization window of mobile device. Analyzing these, authors drew a number of important conclusions. One of them is the fact that determination of partial geocompositions, which are responsible for displaying a specific set of the features, is insufficient and does not ensure the perspicuity of map content. Defining attributes SCAMIN and SCAMAX proved to be satisfactory in the case of point features. For the purposes of correct interpretation of the map and to avoid the effect of "littering" the small screen with too many details in case of the line features and polygons, geometric simplification has to be performed. The research presented in the paper focus on this aspect of generalization. Classical algorithms of simplification were used in the research with properly set parameters on each of the scale levels.

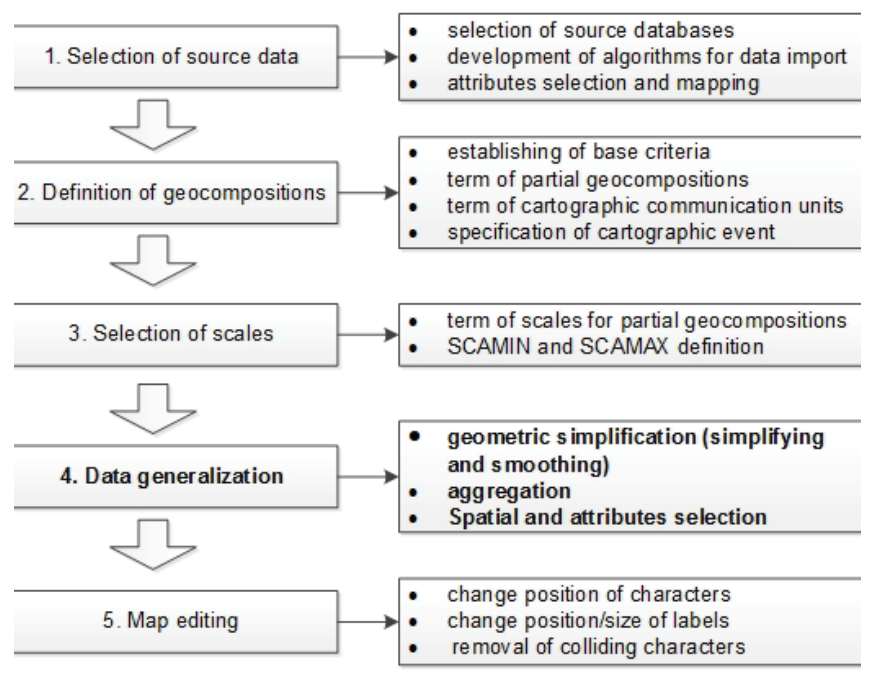

Fig. 1 Schema of the generalization process of spatial data in the system MOBINAV.

Given the requirements of the future user of MOBINAV system, a separate simplification model for each of the layers 
in system was created. These models are combinations of the methods listed below. During the simplification of line features, Douglas-Peucker algorithm was mainly implemented. During the generalization of polygon features, simplification method was applied, maintaining the basic shapes and sizes of the features. The parameter of simplification tolerance and parameter determining the minimum area of the feature was used. Additionally, features within an established distance were merged. Smoothing tool for shape and size of buildings and PEAK method (Polynomial Approximation with Exponential Kernel) were used as well. In addition, selection tool was employed and features with secondary importance to the user of the system during navigation mode, were eliminated. The overriding factor that has been taken into account during the research of simplification methods was the limitation of sharpness of human eyes. It has been taken based on literature that it is about 0,2 millimeter at a distance of 30 centimeters from the human eye [1].

The research covered all 29 vector layers of MODEF data model used in MOBINAV, however the results for only two selected layers are given in the paper, due to limited number of pages. The results for the other layers are similar and the conclusions are suitable for all analyzed data.

\section{EXPERIMENT}

For the purposes of the experiment in this paper, two simplification models were prepared for two layers - PIER_L (wharfs) and VEGETA (vegetation). The parameters of the tested models were modified for different scales. Simplification models have been tested on original data from Szczecin Port. In the next step, statistics were calculated and some of them were represented as relative values for better comparison of simplification effectiveness. The outcomes are rounded to the second decimal place. The results were shown in tabular form and as and spatial visualization. The last stage was their analysis. All research was carried out in ArcGIS software, using ArcCatalog and ArcMap applications and the simplification models were prepared as separate tools with the use of ModelBuilder.

\section{A. Test area}

Part of area of Szczecin Harbour was selected to be a test area. The original data was extracted from ENC (Electronic Nautical Chart) with compilation scale 1: 2000 and Polish Topographic Database with compilation scale 1: 10000 and clipped to the area. Two layers have been selected for the research - VEGETA, presenting vegetation, as an example of polygon features and PIER_L, presenting wharfs, as an example of line features. Thus a set of original features to be simplified was created. Fig. 2 shows the selected test area.

Layer with acronym PIER_L represents wharfs. Apart of general attributes, PIER_L also accepts attribute CATPIR (category of wharf): retaining wall, shore strengthened, wharf and other. The quantitative characteristics of PIER_L in test area are as follows:
- $\quad$ number of features is 277

- number of vertices is 5621

- total length of all features is 79 463,51 meters

- $\quad$ and total volume is $198 \mathrm{~KB}$.

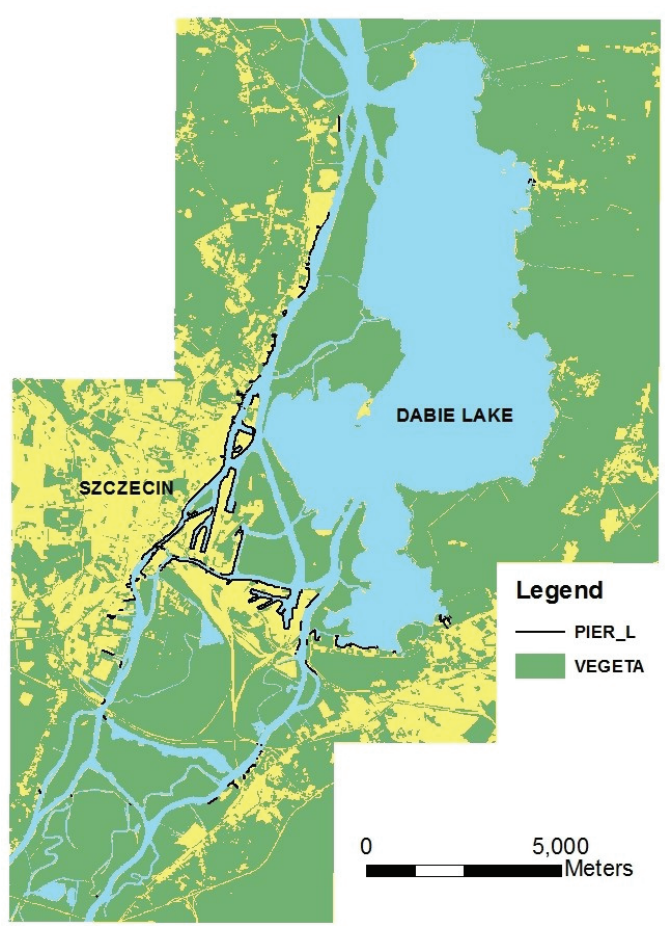

Fig. 2. Part area of Szczecin Port at the scale of 1:100 000 .

Layer with acronym VEGETA represents vegetation. The additional attribute of this layer is CATVEG (category of vegetation), which can take the value of: forest, bush, cultivation, park, agricultural area, grass, rushes and other. The quantitative characteristics in the test area covers:

- number of VEGETA features is 2476

- number of vertices is 179160

- total area of all features is 166,58 square kilometers

- total volume is $3,66 \mathrm{MB}$.

Both layers were processed with dedicated simplification models prepared.

\section{B. Simplification models}

The idea of the research was to build a simplification model for each dataset with the use of simplification tools and selection of proper parameters. The output of each model was a set of simplified features for each output scale. Tools parameters were chosen for each scale separately.

While simplifying layer PIER_L, authors focused only on four scales: 1:7 500, 1:10 000, 1:17 500 and 1:25 000. In smaller scales wharfs will not be displayed. For the generalization of PIER_L networks, simplify line tool was used. It simplifies a line by removing small extraneous bends from it, while maintaining its basic shape. Its operation is based on DouglasPeucker algorithm, which is the most commonly used global 
simplification algorithm in GIS (Geographical Information System). In this algorithm, at the beginning all the vertices between the start and end original vertices are marked to be kept. Next, for every intermediate vertex, its perpendicular distance to the initial simplified line (connecting the start and end original vertices) is calculated. Vertex with maximum distance larger than the founded tolerance is used to divide the initial simplified line into two segments. This step is repeated until the perpendicular distance for each original vertex is smaller than the founded tolerance. All other vertices are deleted.

The basic flow in simplification model for PIER_L, as a model in Model Builder with one output scale is presented in Fig.3.

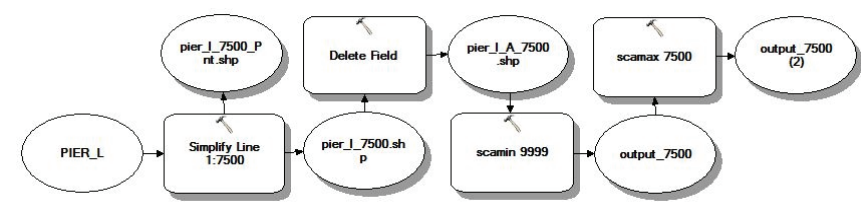

Fig. 3. Simplification model for PIER_L with scale 1:7500.

The layer VEGETA was simplified for each of the scales used in the system and simplify building tool was used. It simplifies the boundary of polygons while retaining their fundamental shape and size. Very important is that simplification process preserves and enhances orthogonality. The tool simplifies separate polygons and group of polygons (connected with straight lines). It is adapted to a whole feature, not only for an feature segment [26].

The basic flow in simplification model for VEGETA with one output scale is presented in Fig.4.

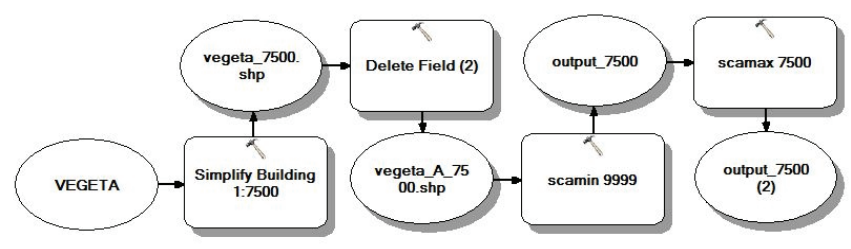

Fig. 4. Simplification model for VEGETA with scale 1:7500.

\section{Selected parameters and assesment criteria}

The limitation of sharpness of human eyes has been taken into account during simplification methods research. As previously mentioned, it is about 0,2 millimeter at a distance of 30 centimeters from the human eye. This value was used as a reference for setting thresholds in the research. The authors decided to implement the following parameters for each of the scales:

- $\quad 1 / 2$ limitation of sharpness of human eyes (further referred to as $\mathrm{A}$ );

- limitation of sharpness of human eyes (further referred to as B);

- $1 \frac{1}{2}$ limitation of sharpness of human eyes (further referred to as $\mathrm{C}$ );

- 2 limitation of sharpness of human eyes (further referred to as D);

- 3 limitation of sharpness of human eyes (further referred to as $\mathrm{E}$ ).

Simplify line algorithm keeps the so-called critical points, which depict the essential shape of a line and remove all other points. The main parameter of this algorithm is maximum allowable offset - the tolerance that determines the degree of simplification. All parameters used in tests are presented in Table 1.

Tab. 1. Parameters (maximum allowable offset) for PIER_L

\begin{tabular}{|c|c|c|c|c|c|}
\hline Scale & A & B & C & D & E \\
\hline $1: 7500$ & $0.75 \mathrm{~m}$ & $1.50 \mathrm{~m}$ & $2.25 \mathrm{~m}$ & $3.00 \mathrm{~m}$ & $4.50 \mathrm{~m}$ \\
\hline $1: 10000$ & $1.00 \mathrm{~m}$ & $2.00 \mathrm{~m}$ & $3.00 \mathrm{~m}$ & $4.00 \mathrm{~m}$ & $6.00 \mathrm{~m}$ \\
\hline $1: 17500$ & $1.75 \mathrm{~m}$ & $3.50 \mathrm{~m}$ & $5.25 \mathrm{~m}$ & $7.00 \mathrm{~m}$ & $10.50 \mathrm{~m}$ \\
\hline $1: 25000$ & $2.50 \mathrm{~m}$ & $5.00 \mathrm{~m}$ & $7.50 \mathrm{~m}$ & $10.00 \mathrm{~m}$ & $15.00 \mathrm{~m}$ \\
\hline
\end{tabular}

During simplifying of vegetation the following parameters have been changed:

- simplify tolerance, that sets the tolerance for simplification (presented in meters);

- minimum area, that sets the minimum area for a simplified polygon to be preserved (presented in square meters). The parameters used during experiments are presented in Table 2.

Tab. 2. Parameters (simplification tolerance and minimum area) for VEGETA

\begin{tabular}{|c|c|c|c|c|c|}
\hline Scale & $\mathbf{A}$ & $\mathbf{B}$ & $\mathbf{C}$ & $\mathbf{D}$ & $\mathbf{E}$ \\
\hline \multirow{2}{*}{$1: 7500$} & $\begin{array}{c}0.75 \mathrm{~m} \\
0.56 \mathrm{~m}^{2}\end{array}$ & $\begin{array}{c}1.50 \mathrm{~m} \\
2.25 \mathrm{~m}^{2}\end{array}$ & $\begin{array}{c}2.25 \mathrm{~m} \\
5.06 \mathrm{~m}^{2}\end{array}$ & $\begin{array}{c}3.00 \mathrm{~m} \\
9.00 \mathrm{~m}^{2}\end{array}$ & $\begin{array}{c}4.50 \mathrm{~m} \\
20.25 \mathrm{~m}^{2}\end{array}$ \\
\hline \multirow{2}{*}{$1: 10000$} & $\begin{array}{c}1.00 \mathrm{~m} \\
1.00 \mathrm{~m}^{2}\end{array}$ & $\begin{array}{c}2.00 \mathrm{~m} \\
4.00 \mathrm{~m}^{2}\end{array}$ & $\begin{array}{c}3.00 \mathrm{~m} \\
9.00 \mathrm{~m}^{2}\end{array}$ & $\begin{array}{c}4.00 \mathrm{~m} \\
16.00 \mathrm{~m}^{2}\end{array}$ & $\begin{array}{c}6.00 \mathrm{~m} \\
36.00 \mathrm{~m}^{2}\end{array}$ \\
\hline \multirow{2}{*}{$1: 17500$} & $\begin{array}{c}1.75 \mathrm{~m} \\
3.06 \mathrm{~m}^{2}\end{array}$ & $\begin{array}{c}3.50 \mathrm{~m} \\
12.25 \mathrm{~m}^{2}\end{array}$ & $\begin{array}{c}5.25 \mathrm{~m} \\
27.56 \mathrm{~m}^{2}\end{array}$ & $\begin{array}{c}7.00 \mathrm{~m} \\
49.00 \mathrm{~m}^{2}\end{array}$ & $\begin{array}{c}10.50 \mathrm{~m} \\
110.25 \mathrm{~m}^{2}\end{array}$ \\
\hline \multirow{2}{*}{$1: 25000$} & $\begin{array}{c}2.50 \mathrm{~m} \\
6.25 \mathrm{~m}^{2}\end{array}$ & $\begin{array}{c}5.00 \mathrm{~m} \\
25.00 \mathrm{~m}^{2}\end{array}$ & $\begin{array}{c}7.50 \mathrm{~m} \\
56.25 \mathrm{~m}^{2}\end{array}$ & $\begin{array}{c}10.00 \mathrm{~m} \\
100.00 \mathrm{~m}^{2}\end{array}$ & $\begin{array}{c}15.00 \mathrm{~m} \\
225.00 \mathrm{~m}^{2}\end{array}$ \\
\hline \multirow{2}{*}{$1: 50000$} & $\begin{array}{c}5.00 \mathrm{~m} \\
25.00 \mathrm{~m}^{2}\end{array}$ & $\begin{array}{c}10.00 \mathrm{~m} \\
100.00 \mathrm{~m}^{2}\end{array}$ & $\begin{array}{c}15.00 \mathrm{~m} \\
225.00 \mathrm{~m}^{2}\end{array}$ & $\begin{array}{c}20.00 \mathrm{~m} \\
400.00 \mathrm{~m}^{2}\end{array}$ & $\begin{array}{c}30.00 \mathrm{~m} \\
900.00 \mathrm{~m}^{2}\end{array}$ \\
\hline \multirow{2}{*}{$1: 100000$} & $\begin{array}{c}10.00 \mathrm{~m} \\
100.00 \mathrm{~m}^{2}\end{array}$ & $\begin{array}{c}20.00 \mathrm{~m} \\
400.00 \mathrm{~m}^{2}\end{array}$ & $\begin{array}{c}30.00 \mathrm{~m} \\
900.00 \mathrm{~m}^{2}\end{array}$ & $\begin{array}{c}40.00 \mathrm{~m} \\
1600.00 \mathrm{~m}^{2}\end{array}$ & $\begin{array}{c}60.00 \mathrm{~m} \\
3600.00 \mathrm{~m}^{2}\end{array}$ \\
\hline \multirow{2}{*}{$\begin{array}{c}25.00 \mathrm{~m} \\
625.00 \mathrm{~m}^{2}\end{array}$} & $\begin{array}{c}50.00 \mathrm{~m} \\
2500.00 \mathrm{~m}^{2}\end{array}$ & $\begin{array}{c}75.00 \mathrm{~m} \\
5625.00 \mathrm{~m}^{2}\end{array}$ & $\begin{array}{c}100.00 \mathrm{~m} \\
1000.00 \mathrm{~m}^{2}\end{array}$ & $\begin{array}{c}150.00 \mathrm{~m} \\
22500.00 \mathrm{~m}^{2}\end{array}$ \\
\hline
\end{tabular}

To assess the performance of the algorithms for various parameters, various statistics have been calculated. First of all the number of deleted vertices in each of the generalized 
layers was used and corresponding to this number of remained vertices in correspondence to original data. This showed the efficiency of an algorithm. Additionally for line feature total length of features and for polygonal features total area of features is given in relation to original set.

To judge computational overload of data in future application, the volume in $\mathrm{KB}$ and $\mathrm{MB}$ is shown. Finally one of the parameters of evaluation is visual assessment of the layers after simplification in a particular scale (one star to five stars). It should be noted that more stars in each field represent a better performance in terms of the assessment results in the selected scale.

\section{Results}

This section compares received results for different scales and various parameters set out above in point $C$.

A summary of statistics for layer PIER_L is given in Table 3 , which contains number of vertices, number of deleted vertices, total length, data volume and visual assessment. While simplifying the layer, the model used does not remove any features. The results of simplification for selected scales are compared with source objects. Number of features was decreased along with the increase of the parameter maximum allowable offset. Using A parameter for scale 1:7 500 this number was reduced by more than a half i.e. until $44 \%$. While for scale 1:25 000 it was reduced almost four times. During the use of the E parameter for scale 1:7 500 it was decreased nearly five times and for scale 1:25 000 almost six times. The results for total length of all features were slightly changed till 3\%. Data volume varied from 157 KB to 133 KB. For larger scales visual assessment is better when using lower value of maximum allowable offset (A and B parameters). Whereas for smaller scales visual assessment is better using bigger values of this parameter.

Tab. 3. Comparison of statistics for PIER_L

\begin{tabular}{|c|c|c|c|c|c|c|}
\hline Scale & & $\mathbf{A}$ & B & $\mathrm{C}$ & D & $\mathbf{E}$ \\
\hline \multirow{5}{*}{$1: 7500$} & $\mathrm{~N}$ of $\mathrm{V}^{\mathrm{a}}[\%]$ & $44,07 \%$ & $32,65 \%$ & $28,13 \%$ & $25,21 \%$ & $22,01 \%$ \\
\hline & $\mathrm{N}$ of $\mathrm{DV}^{\mathrm{b}}$ & 3144 & 3786 & 4040 & 4204 & 4384 \\
\hline & $\mathrm{TL}^{\mathrm{c}}[\%]$ & $99,80 \%$ & $99,54 \%$ & $99,36 \%$ & $99,14 \%$ & $98,82 \%$ \\
\hline & $\mathrm{DV}^{\mathrm{d}}[\mathrm{KB}]$ & 157 & 154 & 146 & 142 & 138 \\
\hline & $\mathrm{VA}^{\mathrm{e}}$ & $* * * * * *$ & $* * * * *$ & $x+7 x$ & $* * * *$ & $* * *$ \\
\hline \multirow{5}{*}{ 1:10000 } & $\mathrm{N}$ of $\mathrm{V}[\%]$ & $38,69 \%$ & $29,11 \%$ & $25,21 \%$ & $22,68 \%$ & $20,53 \%$ \\
\hline & $\mathrm{N}$ of DV & 3446 & 3985 & 4204 & 4346 & 4467 \\
\hline & TL [\%] & $99,71 \%$ & $99,40 \%$ & $99,14 \%$ & $98,91 \%$ & $98,54 \%$ \\
\hline & $\mathrm{DV}[\mathrm{KB}]$ & 147 & 144 & 140 & 138 & 137 \\
\hline & $\mathrm{VA}$ & $* * * * * *$ & $* * * * *$ & $* * * * *$ & $* * * *$ & $* * *$ \\
\hline \multirow{5}{*}{ 1:17500 } & $\mathrm{N}$ of $\mathrm{V}$ [\%] & $30,78 \%$ & $23,63 \%$ & $21,17 \%$ & $19,53 \%$ & $18,09 \%$ \\
\hline & $\mathrm{N}$ of DV & 3891 & 4293 & 4431 & 4523 & 4604 \\
\hline & TL [\%] & $99,48 \%$ & $99,00 \%$ & $98,67 \%$ & $98,32 \%$ & $97,92 \%$ \\
\hline & $\mathrm{DV}[\mathrm{KB}]$ & 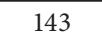 & 141 & 137 & 136 & 135 \\
\hline & VA & $* * * *$ & $* * * *$ & $* * * * *$ & $x \star x+x$ & $* * * *$ \\
\hline \multirow{5}{*}{$1: 25000$} & $\mathrm{~N}$ of $\mathrm{V}[\%]$ & $26,85 \%$ & $21,53 \%$ & $19,23 \%$ & $18,24 \%$ & $16,60 \%$ \\
\hline & $\mathrm{N}$ of DV & 4112 & 4411 & 4540 & 4596 & 4688 \\
\hline & TL [\%] & $99,26 \%$ & $98,75 \%$ & $98,24 \%$ & $97,97 \%$ & $97,23 \%$ \\
\hline & $\mathrm{DV}[\mathrm{KB}]$ & 141 & 139 & 136 & 135 & 133 \\
\hline & $\mathrm{VA}$ & $* * *$ & $* * *$ & $* * * *$ & $* * * *$ & $* * * * *$ \\
\hline
\end{tabular}
a. Number of vertices
b. Number of deleted vertices
c. Total length
d. Data volume
e. Visual assessment

Fig. 5 represents received number of vertices for layer PIER_L. It can be seen that number of vertices is reduced with scale, but the relationship is not quite linear and for smaller scales the differences for different parameters are smaller.

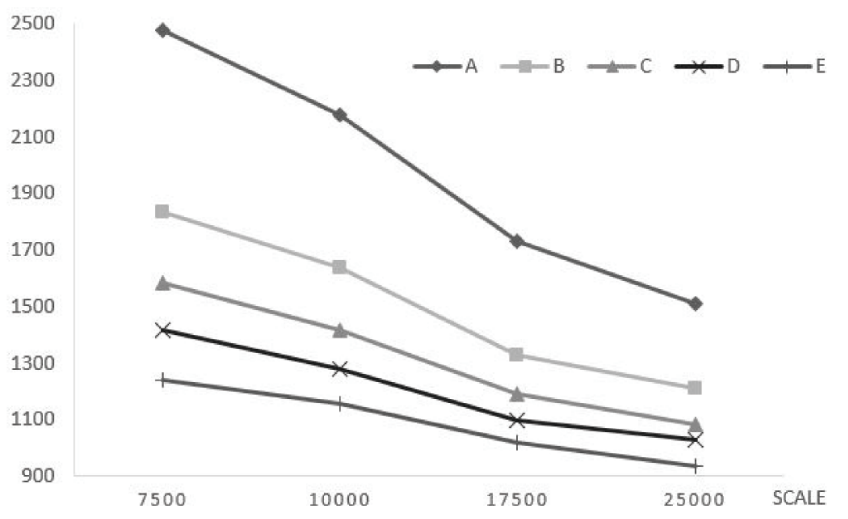

Fig. 5. Number of vertices for PIER_L.

The largest decrease in the number of vertices can be seen using $1 / 2$ limitation of sharpness of human eyes. It is set in the range from 2477 vertices to 1509 vertices. However, the smallest decline can be seen using $\mathrm{E}$ and D parameters. For the latter it is in the range from 1237 to 933.

Fig. 6 represents total length for all features in layer PIER_L. Total length of all features was varied very slightly. It is in the range from 79304.16 meters to 77261.9 meters. The biggest decline in the value can be seen using E parameter. Anyway this time the differences for various parameters are bigger, while the scale gets smaller. The decrease in total length is partly caused by reduced number of features, but also by simplification of shapes.
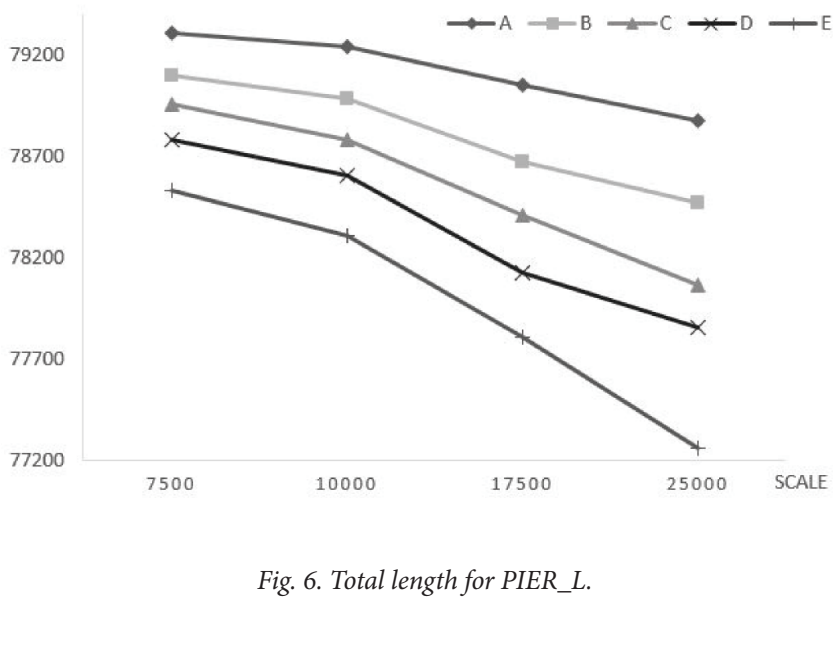

Fig. 6. Total length for PIER_L. 
A comparison of statistics for layer VEGETA is given in Table 4. This time number of features, number of vertices, number of deleted vertices, total area, data volume and visual assessment are given.

Looking at the values in the table, following observations can be made. Increasing of the minimum area parameter was very important for the number of features after simplification. Number of deleted features is in the range from $0.04 \%$ to $74.92 \%$. This means that for the smallest scale only every fourth feature remained. This for sure is major reduction of computational load for application. It can be noticed thus, that joined impact of reduced scale and increased parameter value has an important impact on data. On the other hand, the decrease of number of vertices for particular scales was very similar for each of the parameters (from A to E parameters) - approximately $40 \%$. Values related to total area were changed irregularly. In general they remain on the same level, however slight increase of area may be noticed in most of the cases. This means that the smallest areas are reduced and that simplification of polygons geometry does not mean reduction of the area. Changes in data volume are significant - it was decreased by more than three times, and this is mostly due to reduction of number of features. However it should be noticed that also the number of vertices is reduced significantly in smaller scales, which must have an influence on number of data.

For larger scales visual assessment is better when using lower value of maximum allowable offset and for smaller scales it is better using greater value of this parameter.

Tab. 4. Comparison of statistics for VEGETA

\begin{tabular}{|c|c|c|c|c|c|c|}
\hline Scale & & $\mathbf{A}$ & B & C & D & $\mathbf{E}$ \\
\hline \multirow{6}{*}{$1: 7500$} & $\begin{array}{c}\text { NofFa }^{a} \\
{[\%]}\end{array}$ & $99,96 \%$ & $99,72 \%$ & $99,64 \%$ & $99,43 \%$ & $99,19 \%$ \\
\hline & $\begin{array}{c}\text { Nof }^{b} \\
{[\%]}\end{array}$ & $81,60 \%$ & $76,66 \%$ & $72,14 \%$ & $68,93 \%$ & $64,46 \%$ \\
\hline & NofDV $^{c}$ & 32964 & 41824 & 49909 & 55666 & 63682 \\
\hline & $\mathrm{TA}^{\mathrm{d}}[\%]$ & $99,98 \%$ & $99,98 \%$ & $100,00 \%$ & $99,99 \%$ & $100,02 \%$ \\
\hline & $\begin{array}{l}\mathrm{DV}^{\mathrm{e}} \\
{[\mathrm{MB}]}\end{array}$ & 3,21 & 3,07 & 2,95 & 2,86 & 2,73 \\
\hline & $\mathrm{VA}^{\mathrm{f}}$ & $* * * * *$ & $* * * * *$ & $* * * * *$ & $* * * * *$ & $* * * *$ \\
\hline \multirow{6}{*}{$1: 10000$} & $\begin{array}{c}\text { NofF } \\
{[\%]}\end{array}$ & $99,88 \%$ & $99,64 \%$ & $99,43 \%$ & $99,23 \%$ & $99,15 \%$ \\
\hline & $\begin{array}{c}\text { NofV } \\
{[\%]}\end{array}$ & $80,05 \%$ & $73,52 \%$ & $68,93 \%$ & $65,68 \%$ & $61,32 \%$ \\
\hline & NofDV & 35736 & 47444 & 55666 & 61486 & 69295 \\
\hline & TA [\%] & $99,98 \%$ & $99,99 \%$ & $99,99 \%$ & $99,99 \%$ & $100,02 \%$ \\
\hline & $\begin{array}{c}\text { DV } \\
{[\mathrm{MB}]}\end{array}$ & 3,17 & 2,99 & 2,86 & 2,77 & 2,65 \\
\hline & VA & $* * * * *$ & $* * * * *$ & $* * * * *$ & $* * * *$ & $* * *$ \\
\hline \multirow{6}{*}{$1: 17500$} & $\begin{array}{c}\text { NofF } \\
{[\%]}\end{array}$ & $99,64 \%$ & $99,31 \%$ & $99,19 \%$ & $99,03 \%$ & $98,71 \%$ \\
\hline & $\begin{array}{c}\text { NofV } \\
{[\%]}\end{array}$ & $75,03 \%$ & $67,27 \%$ & $63,15 \%$ & $59,47 \%$ & $54,44 \%$ \\
\hline & NofDV & 44744 & 58642 & 66023 & 72606 & 81622 \\
\hline & TA [\%] & $99,98 \%$ & $99,98 \%$ & $100,02 \%$ & $100,04 \%$ & $100,04 \%$ \\
\hline & $\begin{array}{c}\text { DV } \\
{[\mathrm{MB}]}\end{array}$ & 3,03 & 2,81 & 2,7 & 2,6 & 2,46 \\
\hline & VA & $* * * *$ & $* * * *$ & $* * * * *$ & $* * * * *$ & $* * * *$ \\
\hline
\end{tabular}

\begin{tabular}{|c|c|c|c|c|c|c|}
\hline \multirow{6}{*}{$1: 25000$} & $\begin{array}{c}\text { NofF } \\
{[\%]}\end{array}$ & $99,60 \%$ & $99,19 \%$ & $99,03 \%$ & $98,79 \%$ & $98,22 \%$ \\
\hline & $\begin{array}{c}\text { NofV } \\
{[\%]}\end{array}$ & $70,84 \%$ & $63,15 \%$ & $58,65 \%$ & $55,13 \%$ & $50,03 \%$ \\
\hline & NofDV & 52250 & 66023 & 74078 & 80386 & 89535 \\
\hline & TA [\%] & $99,98 \%$ & $100,02 \%$ & $100,04 \%$ & $100,04 \%$ & $100,09 \%$ \\
\hline & $\begin{array}{c}\mathrm{DV} \\
{[\mathrm{MB}]}\end{array}$ & 2,91 & 2,7 & 2,57 & 2,48 & 2,33 \\
\hline & VA & $* * * *$ & $* * * *$ & $* * * *$ & $* * * * *$ & $* * * *$ \\
\hline \multirow{6}{*}{$1: 50000$} & $\begin{array}{c}\text { NofF } \\
{[\%]}\end{array}$ & $99,19 \%$ & $98,79 \%$ & $98,22 \%$ & $97,46 \%$ & $95,44 \%$ \\
\hline & $\begin{array}{c}\text { NofV } \\
{[\%]}\end{array}$ & $63,15 \%$ & $55,13 \%$ & $50,03 \%$ & $46,23 \%$ & $41,18 \%$ \\
\hline & NofDV & 66023 & 80386 & 89535 & 96328 & 105384 \\
\hline & TA [\%] & $100,02 \%$ & $100,04 \%$ & $100,09 \%$ & $100,19 \%$ & $100,61 \%$ \\
\hline & $\begin{array}{c}\text { DV } \\
{[\mathrm{MB}]}\end{array}$ & 2,7 & 2,48 & 2,33 & 2,22 & 2,06 \\
\hline & VA & $* * * *$ & $* * * *$ & $* * * *$ & $* * * * *$ & $* * * * *$ \\
\hline \multirow{6}{*}{$1: 100000$} & $\begin{array}{c}\text { NofF } \\
{[\%]}\end{array}$ & $98,79 \%$ & $97,46 \%$ & $95,44 \%$ & $88,21 \%$ & $69,14 \%$ \\
\hline & $\begin{array}{c}\text { NofV } \\
{[\%]}\end{array}$ & $55,13 \%$ & $46,23 \%$ & $41,18 \%$ & $37,53 \%$ & $32,10 \%$ \\
\hline & NofDV & 80386 & 96328 & 105384 & 111915 & 121653 \\
\hline & TA [\%] & $100,04 \%$ & $100,19 \%$ & $100,61 \%$ & $100,86 \%$ & $100,98 \%$ \\
\hline & $\begin{array}{c}\mathrm{DV} \\
{[\mathrm{MB}]}\end{array}$ & 2,45 & 2,22 & 2,04 & 1,89 & 1,56 \\
\hline & VA & $* * *$ & $* * *$ & $* * * *$ & $* * * *$ & $* * * * *$ \\
\hline \multirow{6}{*}{$1: 250000$} & $\begin{array}{c}\text { NofF } \\
{[\%]}\end{array}$ & $96,89 \%$ & $78,63 \%$ & $56,83 \%$ & $42,21 \%$ & $25,08 \%$ \\
\hline & $\begin{array}{c}\text { NofV } \\
{[\%]}\end{array}$ & $43,31 \%$ & $34,55 \%$ & $30,26 \%$ & $27,27 \%$ & $23,24 \%$ \\
\hline & NofDV & 101566 & 117263 & 124944 & 130303 & 137531 \\
\hline & TA [\%] & $100,41 \%$ & $100,90 \%$ & $100,46 \%$ & $99,27 \%$ & $96,01 \%$ \\
\hline & $\begin{array}{c}\mathrm{DV} \\
{[\mathrm{MB}]}\end{array}$ & 2,11 & 1,72 & 1,37 & 1,16 & 0,91 \\
\hline & VA & $* *$ & $* *$ & $* * *$ & $* * * *$ & $* * * *$ \\
\hline
\end{tabular}

a. Number of features.

b. Number of vertices.

c. Number of deleted vertices

d. Total area

e. Data volume

f. Visual assessment

Fig. 7 represents received number of features for layer VEGETA. For the smallest value of minimum area (for A parameter and scale 1:7 500 it was equal $0,56 \mathrm{~m}^{2}$ ) only one feature has been deleted. Whereas for its biggest value (for E parameter and scale 1:25 000 it was equal $22500 \mathrm{~m}^{2}$ ) 1855 features have been eliminated - only 621 objects have been remained. It can be noticed that in very small scales (less than $1: 50000)$ the number of features drops rapidly, while for the larger scales it is insignificant in fact. This leads to a conclusion that most of the features remain in these scales, but their shape is being modified. In smaller scales, the impact of method's parameters are much bigger.

Fig. 8 shows the number of deleted vertices for layer VEGETA. 


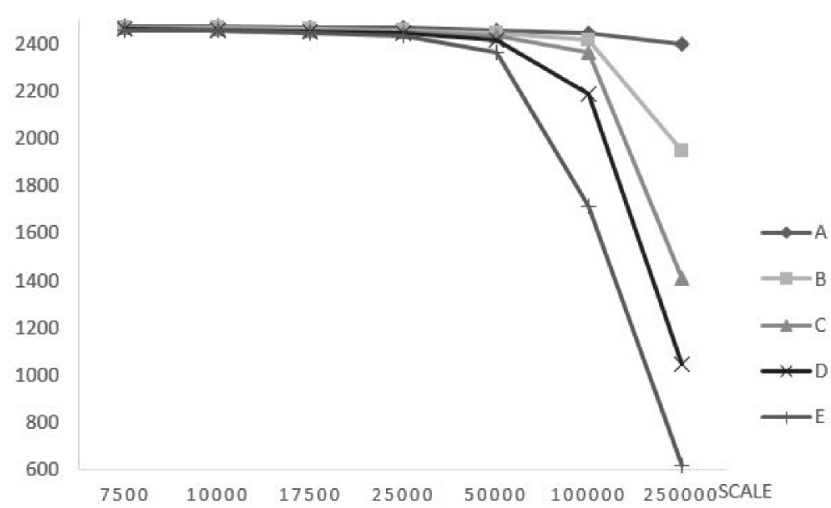

Fig. 7. Number of features for VEGETA.

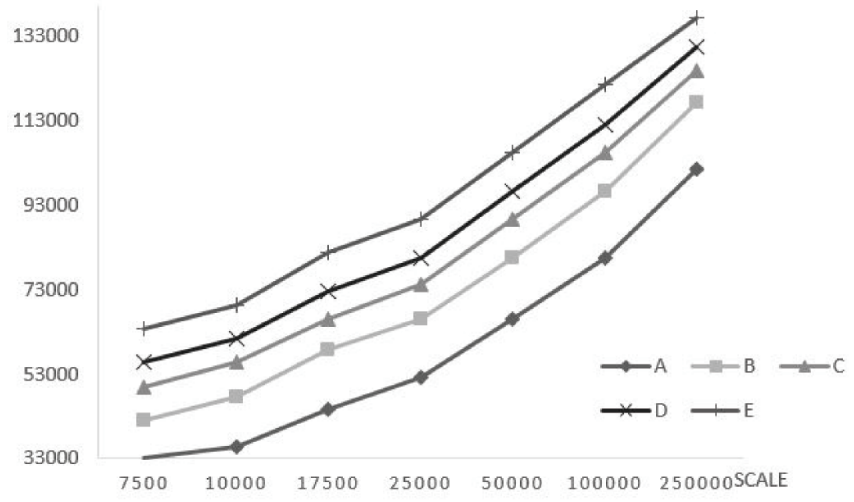

Fig. 8. Number of deleted vertices for VEGETA.

In this case the situation is different. The relationship is almost linear and the reduced nubmer of verticies significantly increases for all scales. The grade of diagrams of number of deleted vertices for particular simplification tolerance are close to each other - their growth is very similar. Minimum number of deleted vertices is 32964 (for A parameter and scale 1:7 500) and maximum is 137531 (for E parameter and scale 1:250 000). For each of simplification tolerance parameters this value increases in a similar way and it is in the range from 68602 (for A parameter) to 75439 (for B parameter). The coclusion might be that although in bigger scales the features remain, their shape is simplified as the vertices are deleted.

\section{CONCLUSIONS}

The paper presented research on geometric generalization methods for maritime mobile navigation system dedicated for touristic purposes in coastal waters. At first, short survey of maritime information system was given in the aspect of mobility and spatial data management. The focus of the research was laid on mobile system, which does not follow any conventional standards for determination of cartographic model. The effort was made to present the problem of data simplification in the model, which is intended for mobile devices like smartphones or tablets.

For this purpose suitable generalization model has been proposed and the experiment on selected layers was performed. The aim of the research was to determine relation between methods parameters and method efficiency. The base for parameters calculation was the value limitation of sharpness of human eyes, which was multiplied by specified factor. The efficiency of methods was determined by a number of vertices, number of features, data volume and additionally visual assessment.

The main conclusion is that, taking into account visual assessment, for bigger scales smaller parameter shall be used and for smaller scale bigger values of parameter performs better. On the other hand analysis of other criteria does not follow directly these findings. Thus, in general it is proposed to use value of $1 \frac{1}{2}$ limitation of sharpness of human eyes ( $\mathrm{C}$ in the research) or to use various parameters for different scales.

The most important factor for real-time mobile application is in fact number of objects, which is why additionally smaller objects shall be completely deleted. Achieved results allow stating, that in case of mobile device and real-time applications the presentation model should include more simplified features than in case of stationary model. However dynamical mobile model should consists of many features generalized separately for different scale ranges.

\section{ACKNOWLEDGMENT}

This scientific research work is supported by National Centre for Research and Development (NCBiR) of Poland (grant No. LIDER/039/693/L-4/12/NCBR/2013) in 2013-2016. The research was carried out in Maritime Technology Ltd.

\section{REFERENCES}

1. Chrobak T., Keller S., Kozioł K., Szostak M., Żukowska M., Basics of digital cartographic generalization, Uczelniane Wydawnictwa Naukowo-Dydaktyczne, Kraków, 2007 (in polish)

2. IHO, S-52 Standard, ed. 6.1, 2014

3. IALA, Operational and Technical Performance of VTS systems V-128, Ed. 4, 2015

4. Hejmanowska B., Kamiński W., Przyborski M., Pyrchla J., (2015), Modern remote sensing and the challenges facing education systems 2 in terms of its teaching, 7th International Confrence on Education and New Learning Technologies EDULEARN 15 Barcelona, Spain, Book Series: EDULEARN Proceedings ISSN: 2340-1117, ISBN: 978-84-606-8243-1, pp. 6549-6558

5. Gotlib D., The methodology of cartographical presentations in mobile localization and navigation ssytems, Prace Naukowe: Geodezja z, 48, Oficyna Wydawnicza Politechniki Warszawskiej, Warszawa, 2011 (in polish)

6. Meng 1., Zipf A., Reichenbacher T. (ed), Map-based mobile services, Springer-Verlag, Berlin Heidenberg, 2005 
7. Świerczyński S., Czaplewski K. (2015), M-Estimation as a Tool Supporting a Vessel Traffic Controller in the VTS System, Polish Maritime Research. Volume 22, Issue 3, Pages 3-13

8. Stateczny, A. and Bodus-Olkowska, I. (2015). Sensor Data Fusion Techniques for Environment Modelling. In Proceedings of the 16th International Radar Symposium (IRS), Dresden, Germany, H. Rohling (Ed.), International Radar Symposium Proceedings, pp. 1123-1128 .

9. Szulwic J., Burdziakowski P., Janowski A., Przyborski M., Tysiąc A., Wojtowicz A., Kholodkov A., Matysik K., Matysik M. (2015), Maritime Laser Scanning as the Source for Spatial Data, Polish Maritime Research Volume 22, Issue 4, pp. 9-14

10. Łubczonek J., Stateczny A., Spatial planning of landbased marine radar sensors by using $3 D$ carthographical model of the port and urbanized areas, Proceedings of CoastGIS 2011, Oostend 2011

11. Stateczny, A., Lubczonek, J. and Kantak, T. (2015). Radar Sensors Planning for the Purpose of Extension of River Information Services in Poland. in Proceedings of the 16th International Radar Symposium (IRS), Dresden, Germany, H. Rohling (Ed.), International Radar Symposium Proceedings, pp. 858-863

12. Stateczny, A.: Full Implementation of the River Information Services of Border and Lower Section of the Oder in Poland. Proceedings of Baltic Geodesy Congress, Gdansk, Poland (2016), pp. 140-146, IEEE, DOI: 10.1109/BGC. Geomatics.2016.33

13. IMO: Resolution MSC.252(83) - Adoption of the revised performance standards for integrated navigation systems (INS), 2007

14. Janowski, A., Nowak, A., Przyborski, M. and Szulwic, J. (2014). Mobile Indicators in GIS and GPS Positioning Accuracy in Cities. In Proceedings of the Joint Rough Set Symposium, Granada and Madrid, Spain, Kryszkiewicz et al. (Eds), Lecture Notes in Artificial Intelligence, 8537, pp. 309-318.

15. Wawrzyniak, N. and Hyla, T. (2014). Managing Depth Information Uncertainty in Inland Mobile Navigation Systems. In Proceedings of the Joint Rough Set Symposium, Granada and Madrid, Spain, Kryszkiewicz et al. (Eds), Lecture Notes in Artificial Intelligence, 8537, pp. 343-350.

16. Kazimierski, W. and Stateczny, A. (2015). Radar and Automatic Identification System Track Fusion in an Electronic Chart Display and Information System. Journal of Navigation, vol. 68, pp 1141-1154.

17. Borkowski, P. (2014). Data fusion in a navigational decision support system on a sea-going vessel. Polish Maritime Research, Vol. 19, 78-85.

18. Szłapczyński R., Śmierzchalski R (2009)., Supporting navigator's decisions by visualizing ship collision risk, Polish Maritime Research. Volume 16, Issue 1, Pages $83-88$

19. Borkowski, P. (2014). Ship course stabilization by feedback linearization with adaptive object model. Polish
Maritime Research, 21, 14-19.

20. Zwierzewicz Z. (2013), On the ship course-keeping control system design by using robust feedback linearization, Polish Maritime Research. Volume 20, Issue 1, Pages 70-76

21. Wlodarczyk-Sielicka M., Stateczny A.: Comparison of selected reduction methods of bathymetric data obtained by multibeam echosounder. Proceedings of Baltic Geodesy Congress, Gdansk, Poland (2016), pp.73-77, IEEE, DOI: 10.1109/BGC.Geomatics.2016.22

22. Stateczny, A. and Bodus-Olkowska, I. (2014). Hierarchical Hydrographic Data Fusion for Precise Port Electronic Navigational Chart Production. In Telematics in the Transport Environment, Proceedings of the 14th International Conference on TST, Katowice-Ustroń, Poland, J. Mikulski (Ed.), Communications in Computer and Information Science, 471, 359-368.

23. Wlodarczyk-Sielicka, M., Stateczny, A.: Clustering Bathymetric Data for Electronic Navigational Charts. The Journal of Navigation vol. 69, issue 5, pp 1143-1153 (2016)

24. IMO NCSR 1/28, Draft e-navigation strategy implementation plan, 2014, http://www.imo.org/en/ OurWork/Safety/Navigation/Documents/enavigation/ SIP.pdf

25. W. Kazimierski, I. Bodus-Olkowska, M. WłodarczykSielicka, G. Zaniewicz, The concept of cartographic presentation model in mobile navigation system for inland waters, Annals of Geomatics 2015, Vol. XIII, 4(70), s, 335-348,

26. V. Droppova, The tools of automated generalization and building generalization in an ArcGIS environment, Slovak Journal of Civil Engineering, Volume 19, Issue 1, Pages 1-7, 2011

\section{CONTACT WITH THE AUTHOR}

\author{
Witold Kazimierski \\ e-mail:w.kazimierski@marinetechnology.pl \\ Marine Technology Ltd. \\ Szczecin \\ Poland
}

